\title{
ENTREVISTA CON JAVIER GORRAIS
}

\section{INTERVIEW WITH JAVIER GORRAIS}

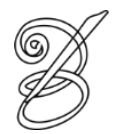 \\ Entrevistadora: Dra. Ana María GENTILE ${ }^{1}$ \\ Universidad Nacional de La Plata, Argentina
}

\begin{abstract}
Tavier Gorrais es Profesor y Licenciado en Letras y Traductor Público en Francés por la Facultad de Humanidades y Ciencias de la Educación de la Universidad Nacional de La Plata. Realizó estudios de Master en la Université de Bretagne Occidentale bajo la dirección del Dr. Michael Rinn sobre «L'écriture de soi comme réponse à l'autre: W ou le souvenir d'enfance de Georges Perec ». Actualmente se encuentra terminando su doctorado en Letras con una tesis intitulada "El proyecto creador de Georges Perec en relación con la construcción de la identidad y los debates en torno a la memoria del Holocausto entre 1945 y 1982”, bajo la dirección de la Dra. Margarita Merbilhaá y la codirección del Dr. Michael Rinn. Como especialista de la obra de Georges Perec, nos habla de su experiencia de crítica y de traducción de la obra perecquiana.
\end{abstract}

RECEBIDO EM: janeiro 2019

ACEITO EM: janeiro 2019

PUBLICADO EM: abril 2019 
Ana María Gentile (AMG): ¿Qué inquietudes o preocupaciones propias de la estética de Georges Perec lo han llevado a querer estudiar su obra y traducir algunos de sus escritos?

Javier Gorrais (JG): En primer lugar, cabe reconocer que la escritura de Georges Perec responde a múltiples procesos de identificación en los que el par sujeto-autor constituye el núcleo de un proyecto que podríamos denominar de doble entrada, es decir, una empresa inescindible e indecidible entre, por un lado, aquello que responde a una búsqueda de carácter autobiográfico y, por otro, lo que resulta de sus trabajos dentro de la invención literaria, entre la exploración de sí y la creación estética, ambas atravesadas por la experiencia escrituraria. En este sentido, en su producción, los modos de representación y los desvíos de las formas tradicionales de invención se convierten en una característica esencial, pero también en una instancia que da cuenta de la inestabilidad y de la desaparición, resultado de la ausencia y el silencio, que se indaga desde la escritura. Esto último encuentra su razón de ser en la génesis de esos procesos de escritura, pero también en la historia individual que lleva a Perec a arrojarse al campo literario, con el propósito de involucrarse en un proyecto estético, por medio de posicionamientos que interpelan la conciencia colectiva frente al horror de la Historia, la Shoah,

166 la diáspora y la falta de tradiciones o herencia. Recuérdese su condición de judío y de huérfano, aspectos que señalan toda su escritura.

AMG: Esta indecidibilidad a la que se refiere expone, de alguna manera, las condiciones de producción y de recepción de la literatura del siglo veinte. ¿De qué forma se explicitan esas imposibilidades o esos intercambios entre lo factual y lo ficcional en Perec?

JG: La semblanza de Perec, recién esbozada, puede contribuir a desandar el itinerario literario y a vivificar los debates en torno a sus intervenciones por fuera de la ficción: me refiero a esa vasta escritura orientada hacia cuestionamientos literarios desde lo teórico, la crítica, proyectos inconclusos o bien las discusiones políticas en relación directa con la literatura y sus actores. Por eso, si bien su obra se ha destacado por lo exclusivamente literario, en los últimos años se ha vuelto oportuno y necesario interrogar esta escritura que roza los bordes de la ficción y se mezcla con ella, fundiéndose en esa indecidibilidad de la que hablaba. Para poder dar sentido a esto, basta con remitirse a la cantidad de textos publicados de manera póstuma. El carácter potencial de la escritura perecquiana encuentra su espacio pertinente y favorable en esas apuestas editoriales, que en nuestro caso se relaciona con las posibilidades que habilita la práctica inasible, cuestionable y asediada que es la traducción. Los diálogos con la recepción y las condiciones en las que estas se producen se hallan en constante situación de entrega y de 
apertura, invitando y exigiendo formas inacabadas y siempre en proceso de escritura, reescritura, traducción o crítica, como contrafirmas inevitables de todo ejercicio escriturario.

AMG: ¿Qué interés pueden encontrar esas intervenciones de Perec en los distintos campos, tanto para su estudio como para la traducción? ¿Qué aporta a las discusiones o a las investigaciones la publicación de esos escritos póstumos?

JG: Estos textos póstumos son portadores de una gran riqueza para los estudios de la obra de Perec y algunos de ellos cobran una importancia notable respecto de esa búsqueda autobiográfica y ese entrecruzamiento de voces al que antes aludía. Entre esos trabajos o ejercicios de escritura, resultan significativos algunos libros publicados tras su desaparición: Penser/Classer (1985), primero editado por Hachette y luego por Éditions du Seuil (cuenta con una traducción inmediata de Carlos Gardini para Gedisa: Pensar/Clasificar, Barcelona, 1986 y sus posteriores ediciones); L'infra-ordinaire (Seuil, 1989), traducido por primera vez al castellano por Mercedes Cibrián en 2008 para Impedimenta (España) y luego traducido en 2013 por Jorge Fondebrider para la editorial argentina Eterna Cadencia (en ambos casos, Lo infraordinario); Je suis né (1990), traducido por Diego Guerrero para la editorial española Abada (2006) y luego por Fondebrider (2012) para Eterna Cadencia (en ambos casos, Nacî); finalmente, L.G. Une aventure des années soixante ${ }^{2}$ (1992), publicación fundamental de los posicionamientos estéticos de Perec y clave para comprender el carácter colectivo y plural de su escritura, como también para aproximarse a la dimensión ética que atraviesa su proyecto creador. Este libro reúne artículos escritos por Perec y un grupo de intelectuales, mayoritariamente jóvenes comunistas, para lo que iba a ser una revista de cultura, cuyo nombre era La Ligne générale, en clara conexión con la película homónima de Eisenstein.

AMG: ¿Ese es el libro que usted tradujo al español y que será publicado en Argentina?

JG: Claro, L.G. Une aventure des années soixante es el libro de Perec que acabo de traducir y se encontrará disponible en las librerías, en 2019. Inédito en lengua española, será editado para Argentina y Latinoamérica por la editorial argentina Waldhuter, bajo el título L.G. Una aventura de los años sesenta ${ }^{3}$. La traducción, corrección y edición fue culminada en 2018, tras un largo trabajo de preparación. Fue una propuesta que le acerqué a la editorial, por razones suficientes y válidas que ya detallaré. El proyecto recibió un significativo apoyo desde la editorial; creo que el tratarse de Georges Perec facilitó un poco el voto positivo de la editorial, aunque hay que reconocer que el poco conocimiento de este libro para quienes no se dedican a 
la literatura o a la obra de este gran escritor, podría haber sido un obstáculo. Afortunadamente, esto fue resuelto con sólidos fundamentos del por qué valía la pena encarar dicha empresa.

AMG: ¿Cómo ha sido el proceso o la toma de decisiones de traducir el libro en un contexto de indecidibilidades que, en este caso, responden a la crisis que sufren actualmente las editoriales?

JG: Intentaré ser breve en cuanto a la historia de la traducción y publicación. Mi interés por traducir este libro reside en varios aspectos. Uno de ellos es de índole personal, pues me parece un conjunto de artículos fascinante. Otra razón tiene que ver con un apego más profesional, si se quiere, ya que los escritos que componen este volumen han acompañado parte de mis investigaciones y de mis producciones académicas, tanto en Francia como en Argentina. Mi formación universitaria y mis inquietudes han pasado por estos dos países y las exigencias de esos mundos, tan dispares en algunas cuestiones, exigen producir. Ahora bien, por fuera de toda inclinación personal, el desafío de traducir este libro encuentra su ocasión en la ausencia de traducción previa al español, lo cual, también es cierto, expone cualquier trabajo a la lupa de la

168 crítica (muchas veces replegada sobre sí misma y en la saciedad). Pero, al mismo tiempo, vi la posibilidad de abrir el diálogo a los intercambios y lecturas propias de prácticas de legibilidad de diversos destinarios, que, sea cual fuere su procedencia (académicos, universitarios, especialistas, aficionados), siempre generan otros modos de exteriorización que enriquecen el proyecto (y la aventura de su concreción): nuevas traducciones, artículos críticos, proyectos de escritura creativa y hasta revisión, si se quiere, de publicaciones en torno a temas, figuras, libros y autores relacionados con ese texto que acaba de ver la luz en una lengua extranjera, abierta a la hospitalidad.

AMG: ¿Qué elementos considera sustanciales para esos debates? ¿Qué impacto puede tener en los lectores de este siglo?

JG: Como respuesta, siempre me apoyo en la potencialidad e incluso en lo imprevisible, pero también me gusta detenerme en esa imposibilidad, que es algo propio de la tarea de escritura y que nos vuelve responsables, como sostenía Maurice Blanchot. Para mí, L.G. Una aventura de los años sesenta permite indagar sobre algunos aspectos primordiales de la escritura de Perec, pero al mismo tiempo da cuenta de un recorrido estético y político que tiene que ver con los modos de leer la cultura y el arte contemporáneo, posicionándolo en el centro de los debates y, a su vez, en el campo literario francés. El grupo de intelectuales que conformaba el proyecto de 
revista La Ligne générale tenía como propósito reflexionar sobre los objetivos y las funciones del arte y la literatura, algo que Perec definía como un movimiento, un organismo de investigación, un sistema de referencia y documentación. La Ligne générale pretendía discutir sobre las posibilidades de los compromisos literarios con el fin de dar forma a una literatura épica, susceptible de aprehender un espíritu renovado y recuperar los debates y las prácticas artísticas que tuvieron lugar desde el fin de la Segunda Guerra y moldear un nuevo modo de pensar las intervenciones en el campo cultural. En esta perspectiva, Perec entiende que una revista como la que están gestando - y esto es en 1959, antes de su debut como autor literariodebe contemplar un panorama de la cultura, una crítica, un diccionario de ideas contemporáneas, nuevas bases culturales y políticas, una nueva conciencia, es decir, todas esas posibilidades que están latentes como gestos detrás de cualquier publicación, lo que una traducción en lengua extranjera enciende desde el momento que se entrega a los lectores. Puede decirse que la traducción comparte esas condiciones o al menos se siente interpelada desde esos requerimientos. Por eso, si la revista encontraba su necesidad en el despertar a la crítica ociosa y encauzarla en los caminos del pensamiento transformador y revolucionario, en cuanto a los diversos modos de posicionarse en campo cultural, una traducción no hace sino acoger esa exigencia y responder desde su voz, siempre otra, con una nueva legibilidad. Creo que en este último rasgo, en las nuevas legibilidades o las otras legibilidades (que no es otra cosa más que la potencialidad o lo posible), se encuentra el valor de estas apuestas editoriales. Esperemos que los lectores reciban el libro con benevolencia y espíritu crítico, el resto es otro asunto.

AMG: Por supuesto, vayamos al libro en sí y a lo que nos propone.

JG: Volvamos a la revista para la cual se escriben los artículos que se presentan en el libro en cuestión. La necesidad de publicaciones como la de La Ligne générale, para la Francia de los años sesenta, responde a la ausencia de nuevas propuestas en ese ámbito, al menos en las tendencias de izquierda, con quienes se busca dialogar: Arguments, Les Temps Modernes, Lettres Nouvelles, Cahiers des saisons, Tel Quel, Europe, Esprit y Nouvelle Revue Française. Un proyecto de estas características exhibe los interlocutores e instala los debates, indicando la dirección hacia la cual se orienta el perfil ideológico y literario del grupo, pero también de la escritura de Perec y sus estrategias de posicionamiento en relación con las manifestaciones artísticas y literarias del siglo XX, que lo llevan a construir su proyecto creador, su programa de escritura, y a configurar escenificaciones de la literatura, en constante reflexión sobre los modos del decir y sus nuevas direcciones. En este sentido, la revista La Ligne générale en tanto 
proyecto y la publicación de L.G. une aventure des années soixante como libro dan vida a las discusiones sobre las posibilidades de la literatura y la actualidad del arte, al tiempo que ofrecen al lector el trazo del itinerario de Perec en su formación autoral, pues encuentra allí el germen de sus inicios literarios. La escritura crítica prepara el terreno para su irrupción y su inserción en la literatura, poniendo en debate las condiciones de producción del arte contemporáneo y los modos imaginarios de representación de la realidad, como forma de renovar las creaciones artísticas en la Francia de los años sesenta. Por ejemplo, mientras este proyecto de revista se construía desde la escritura crítica y colectiva, Perec escribía algunas novelas: L'attentat de Sarajevo (escrita hacia 1957 y editada por Seuil en 2016) y Le Condottière (escrita entre 1957 y 1960, finalmente editada por Seuil en 2012), ambas publicadas después de su muerte y recientemente traducidas al español (El condotiero, Anagrama, 2013 y El atentado de Sarajevo, El cuenco de plata, 2017). Así, su escritura se fue moldeando, a partir de esas primeras discusiones para luego continuar en un infatigable recorrido colmado de investigaciones sobre la forma, la lengua y el ejercicio escriturario como potencialidad y compromiso con nuevas concepciones literarias.

AMG: ¿Cómo se estableció su traducción y qué estrategias tuvo en cuenta a la hora de recuperar esos diálogos con la época, para poder entregar un producto acorde a nuestros tiempos?

JG: Llevé adelante la traducción de L.G. una aventura de los años sesenta en diálogo con la tradición de traducciones en lengua española de los escritos de Perec y atendiendo al estado de la recepción y traducciones de los autores y libros allí referidos. De este modo, pude establecer determinados recorridos de legibilidades de la comunidad hispanoparlante y dar cuenta de las posibilidades que trae consigo el traducir obras como esta. En este sentido, mi trabajo de traducción se vio atravesado por una ardua tarea de investigación, tanto del tema que nos involucra (Georges Perec y su obra), como del contexto y el marco de producción y de recepción en los que se insertan los debates que se pretenden impulsar desde los escritos reunidos. A su vez, me fue necesario llevar a cabo un estudio del campo literario, particularmente en Francia, para aprehender los términos en los que se presentan las discusiones y poder comunicarlas dentro de la tónica con se desarrollan en la crítica y la teoría literaria. Esto considerando y poniendo en cuestionamiento las condiciones de producción y de recepción de esas lecturas en el ámbito de las traducciones al español. A su vez, se dio la aparición de nuevos desafíos: traducir las obras que nunca habían sido traducidas al español. Con esto me refiero a las obras 
literarias que se mencionan en el libro y con las cuales entra en diálogo, es decir, cómo traducir títulos, pasajes, cómo dar cuenta de una primera vez de algo que tiene más de medio siglo de existencia y que ha pasado inadvertido frente a la mirada de las apuestas editoriales. En algunos casos, autores no tan populares para el gran público, en otros célebres escritores, aún sin traducir. Pero también, el tiempo y los espacios, las geografías, llevan a una constante pugna con lo ya existente, donde entran en juego factores culturales y estéticos, o si se quiere ciertas configuraciones del gusto. De esta forma, mi traducción busca enriquecer los debates en torno a las reflexiones sobre la cultura, el arte y la literatura, pero también contribuir al desarrollo de nuevos diálogos a partir de la presentación de obras inéditas que dan lugar a nuevas manifestaciones: lecturas críticas, investigaciones y traducciones de obras que rodean a ese trabajo.

AMG: Antes hablaba de una imprevisibilidad, que pueden traducirse en lo potencial de toda obra y más tratándose de un miembro del Oulipo. ¿Cómo siguen sus trabajos o proyectos en función con la apertura a la que da lugar su traducción?

JG: Las posibilidades en tanto posibilidad se encuentran siempre agazapadas, al acecho, pensando en lo posible. Lo posible en mi caso se ha topado con cierta continuidad. Esos diálogos, a los que me refería al hablar de las posibilidades que se abren a partir de la traducción de obras inéditas, los veo reflejados en la extensión del proyecto que me interpela desde lo personal, tanto en la investigación académica como especialista en literatura francesa y en la obra de Perec, como también desde la traducción en el marco de la investigación en traductología, que involucra desde mi participación en un proyecto de investigación de la Universidad Nacional de La Plata. Como resultado de la publicación de este título, se encuentra en proceso la traducción de otro libro de Perec, inédito en lengua española, que, de alguna manera, es una especie de anuncio, una suerte de programa y de comentario de lo que se lee en L.G una aventura de los años sesenta. A su vez, contribuye a reponer el contexto que le da lugar al libro que acabo de traducir. Me refiero a 56 lettres à un $a m i^{4}$, editado en 2011 por la editorial francesa Le Bleu du ciel y que reúne cartas escritas por Perec entre 1959 y 1969, la mayoría en torno a la literatura, actores culturales y, fundamentalmente, La Ligne générale. Por eso, este proyecto de traducción de escritos de Perec ofrece a los lectores trabajos nunca antes editados en español y favorece la posibilidad de abrir nuevos debates dentro del campo literario francés de los años sesenta y su recepción a más de cincuenta años, en esta comunidad de lectores. Por último, considero necesario destacar que semejantes iniciativas permiten, no solo 
disfrutar de los escritos de este autor francés, sino también pensar y descifrar las distintas legibilidades desde la práctica incesante e inacabada de la traducción.

AMG: Es sin duda un campo de indagación, de crítica y de traducción inagotable. Le agradezco mucho su disposición para esta entrevista y le deseo muchos éxitos en su carrera como traductor.

\footnotetext{
${ }^{1}$ Ana María GENTILE. Doctora en Ciencias del Lenguaje, Université de Rouen, Francia. Se desempeña como Profesora de traducción literaria y traducción científico-técnica en francés I en la Universidad Nacional de La Plata. Es directora de proyectos de investigación y miembro del comité asesor del Área de Investigación en Traductología, Instituto de Investigaciones en Humanidades y Ciencias Sociales (IdIHCS), Consejo Nacional de Investigaciones Científicas y Técnicas (CONICET). ORCID : https://orcid.org/0000-0002-0680-5999; e-mail : anamariagentile@gmail.com

${ }^{2}$ Perec, Georges. L.G. Une aventure des années soixante, París: Seuil, 1992.

${ }^{3}$ Perec, Georges. L.G una aventura de los años sesenta, Buenos Aires: Waldhuter, 2019.

${ }^{4}$ Perec, Georges. 56 lettres à un ami, París: Le Bleu du ciel, 2011.
} 